\title{
PENGARUH USER INTERFACE QUALITY, INFORMATION QUALITY, PERCEIVED SECURITY, PERCEIVED PRIVACY, BELIEF, DAN KNOWLEDGE TERHADAP NIAT BELI BARANG DI WEBSITE E-COMMERCE DI INDONESIA.
}

\author{
Herison Halim \\ Program Studi Magister Manajemen Universitas Tarumanagara \\ herisonhalim50@gmail.com
}

\begin{abstract}
E-Commerce or better known as electronic commerce is the dissemination, buying, selling, marketing of goods and services through electronic systems. In Indonesia, ECommerce began to show a fairly rapid development. Factors Knowledge them about ECommerce that makes the users of E-Commerce in Indonesia feel unsure to make transactions on the E-Commerce website. In addition to Knowledge factors, other factors such as User Interface Quality, Information Quality, Perceived Security and Perceived Privacy, are factors that can trigger a person to be able to perform transactions in ECommerce. Then the factor of trust, attitude can also affect a person in doing transactions on E-Commerce website. This study aims to find out how the influence of user interface quality, information quality, perceived security, perceived privacy variables via trust variables, and belief variables, and knowledge through attitude variable to purchase intention in ECommerce website in Indonesia. analysis method used is path analysis method, data source used is primary data. in this study also carried out the distribution of questionnaires as much as 300 respondents with the requirement that the prospective respondents must have or often give goods on E-Commerce website. The results There are variables that significantly affect the trust variables of User Interface Quality, Information Quality, Perceived Privacy. While other variables such as Belief, and Knowledge, significant effect on the Attitude someone to act or conduct transactions in E-Commerce website in Indonesia.
\end{abstract}

Keywords: E-Commerce, User Interface Quality, Information Quality, Perceived Security, Perceived Privacy, Trust, Attitude, Purchase Intention

\section{PENDAHULUAN}

E-Commerce atau yang lebih dikenal sebagai electronic commerce atau perdagangan elektronik merupakan penyebaran, pembelian, penjualan, pemasaran barang dan jasa melalui sistem elektronik. Perkembangan E-Commerce telah menyebar ke berbagai negara, khususnya indonesia telah berkembang pesat dimana menurut data Lembaga kajian ekonomi Center of Reform on Economics (CORE) Indonesia, memperkirakan bahwa nilai perdagangan elektronik atau yang lebih akrab dengan sebutan E-Commerce di Indonesia pada tahun 2016 mencapai US\$24.6 miliar, atau setara dengan 319,8 Triliun rupiah. Di indonesia, E-Commerce perlahan-lahan mulai menunjukkan perkembangan yang cukup pesat. Meningkatnya pengguna internet tidak bisa dipungkiri menjadi salah satu faktor pemicu pertumbuhan bisnis toko online di negara ini. Namun di indonesia, sistem E-Commerce ini tidak begitu populer, karena banyak pengguna internet yang masih meragukan kemanan dari sistem E-Commerce sendiri. Kurangnya pengetahuan mereka mengenai E-Commerce itu membuat para pengguna $E$-Commerce di indonesia merasa kurang yakin untuk melakukan transaksi di website E-Commerce tersebut. Selain faktor pengetahuan, faktor lain seperti kualitas tampilan website, kelengkapan informasi pada website, keamanan terhadap data pribadi, merupakan faktor yang dapat memicu seseorang untuk dapat melakukan transaksi di E-Commerce. Kemudian tingkat kepercayaan yang belum begitu baik untuk transaksi di website E-Commerce menjadi sebuah kendala bagi setiap calon pembeli di website $E$ - 
Commerce itu sendiri. Selain itu faktor etika (Attitude) juga dapat mempengaruhi seseorang dalam melakukan transaksi di website E-Commerce.

Berdasarkan latar belakang diatas, maka rumusan masalah yang dapat dirumuskan adalah sebagai berikut:

1. Bagaimana Pengaruh User Interface Quality terhadap niat pembelian produk di website $E$ Commerce di indonesia?

2. Bagaimana pengaruh Information Quality terhadap pembelian produk di website $E$ Commerce di Indonesia?

3. Bagaimana pengaruh Perceived Security terhadap pembelian produk di website $E$ Commerce di Indonesia?

4. Bagaimana pengaruh Perceived Privacy terhadap pembelian produk di website $E$ Commerce di Indonesia?

5. Bagaimana pengaruh Belief terhadap niat pembelian produk di website E-Commerce di indonesia?

6. Bagaimana pengaruh Knowledge terhadap niat pembelian produk di website $E$ Commerce di indonesia?

7. Bagaimana pengaruh Trust dan Attitude terhadap niat pembelian produk di website $E$ Commerce di indonesia?

Berdasarkan rumusan masalah diatas, maka untuk menjawab persoalan tersebut selanjutnya dilakukan penelitian dengan tujuan:

1. Untuk mengetahui seberapa besar pengaruh User Interface Quality terhadap niat pembelian produk di website E-Commerce di indonesia.

2. Untuk mengetahui seberapa besar pengaruh Information Quality terhadap niat pembelian produk di website E-Commerce di indonesia.

3. Untuk mengetahui seberapa besar Perceived Security terhadap niat pembelian produk di website E-Commerce di indonesia.

4. Untuk mengetahui seberapa besar pengaruh Perceived Privacy, terhadap niat pembelian produk di website $E$-Commerce di indonesia.

5. Untuk mengetahui seberapa besar pengaruh Belief terhadap niat pembelian produk di website $E$-Commerce di indonesia.

6. Untuk mengetahui seberapa besar pengaruh Knowledge terhadap niat pembelian produk di website $E$-Commerce di indonesia.

7. Untuk mengetahui seberapa besar pengaruh Trust dan Attitude akan berpengaruh terhadap niat pembelian produk di website $E$-Commerce di indonesia.

\section{TINJAUAN PUSTAKA}

Adapun tinjauan pustaka yang digunakan pada penelitian ini adalah User Interface Quality yaitu User Interface sebagai saluran dimana konsumen dapat berinteraksi dengan penyedia layanan elektronik Gunmmerus et al. (2004). Information Quality yaitu Kualitas informasi didefinisikan sebagai presepsi pelanggan terhadap kualitas informasi tentang produk atau layanan yang disediakan oleh sebuah website Park Dan Kim (2003). Perceived Security yaitu persepsi keamanan sebagai kemungkinan kepercayaan subjektif yang dimiliki konsumen bahwa informasi pribadi mereka (dalam aspek perdata dan moneter) tidak akan dilihat, disimpan, dan dimanipulasi oleh pihak lain selama dalam perjalanan dan penyimpanan, sehingga secara secara konsisten menimbulkan harapan kepercayaan diri mereka. Flavia'n and Guinalı'u (2006). Perceived Privacy yaitu Persepsi privasi berkaitan dengan kemampuan konsumen untuk mengendalikan penyebaran informasi selama transaksi atau perilaku konsumsi konsumen tersebut dari orang lain di sekitarnya (Eid, 2011). Belief yaituKeyakinan adalah suatu sikap yang ditunjukkan oleh manusia saat dia merasa cukup tahu dan menyimpulkan bahwa dirinya telah mencapai kebenaran. Karena keyakinan merupakan suatu sikap, maka keyakinan seseorang tidak selalu benar atau, keyakinan semata bukanlah jaminan kebenaran Vardiansyah (2008). Knowledge yaitu pengetahuan merupakan hasil dari 
tahu dan ini terjadi orang melakukan pengindraan terhadap sesuatu objek tertentu Notoatmodjo (2007). Trust yaitu Trust merupakan pondasi dari sebuah bisnis. Suatu transaksi bisnis antara dua pihak atau lebih akan terjadi apabila masing-masing saling mempercayai. Kepercayaan (Trust) ini tidak begitu saja dapat diakui oleh pihak lain/mitra bisnis, melainkan harus dibangun mulai dari awal dan dapat dibuktikan. Trust telah dipertimbangkan sebagai katalis dalam berbagai transaksi antara penjual dan pembeli agar kepuasan konsumen dapat terwujud sesuai dengan yang diharapkan Yousafzai (2003). Attitude yaitu menunjukkan sikap sebagai "evaluation disposition toward some object, based on cognitions, affective reactions, behavioral intentions, and past behaviors, that can influence cognitions, affective responses, and future intentions and behaviors" atau landasan dalam evaluasi terhadap objek tertentu, berdasarkan pada kognisi, reaksi afektif, niat dalam berperilaku, \& perilaku dari masa lalu, yang dapat berperngaruh terhadap kognisi, respons afektif, \& niat dalam berperilaku, sekaligus terhadap perilaku di masa depan Philip Zimbardo dan Michael Leippe (1991). Niat Beli yaitu Purchase Intention (niat beli) merupakan bagian dari komponen perilaku dalam melakukan konsumsi atau pembelian. Purchase Intention adalah tahap kecenderungan konsumen untuk bertindak sebelum keputusan membeli benar-benar dilaksanakan. Purchase Intention dapat didefinisikan sebagai kemungkinan bila pembeli bermaksud untuk membeli produk yang secara positif berhubungan terhadap presepsi keseluruhan pada akuisisi dan transaksi nilai.. Bian dan Moutinho (2011).

\section{Model Penelitian}

Model pada penelitian ini dapat dilihat pada gambar di bawah ini:

Gambar 1.1

\section{Model Penelitian}

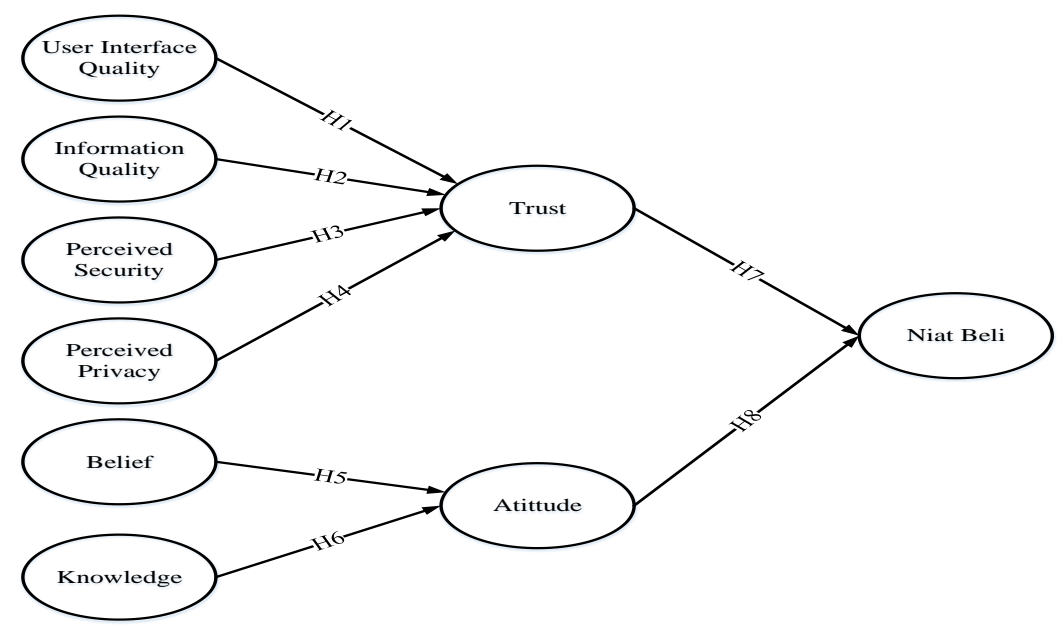

\section{METODE PENELITIAN}

\section{Jenis Penelitian}

Penelitian ini menggunakan metode penelitian deskriptif karena dalam pelaksanaannya meliputi data, analisis data yang diperoleh.

\section{Sumber Data}

Pada penelitian ini, data yang digunakan adalah data primer yaitu melakukan penyebaran kuesioner.

\section{Metode Analisis}

Berdasarkan tujuan dari penelitian ini, maka Metode analisis yang digunakan adalah Metode Analisis Jalur (Path Analysis).

\section{HASIL PENELITIAN}

\section{Uji Validitas}


Berikut ini merupakan hasil uji validitas dari keseluruhan responden dari penelitian ini. Nilai standar yang digunakan untuk melihat apakah suatu instrumen valid atau tidak adalah sebesar 0,3 dimana ketika korelasinya lebih besar dari 0,3 maka dapat dinyatakan bahwa faktor tersebut mempunyai nilai konstruk yang kuat.

\section{Tabel 1.1 Hasil Uji Validitas}

$\begin{array}{llll}\text { Indikator } & \begin{array}{l}\text { Corrected } \\ \text { Item-Total }\end{array} & \begin{array}{l}\text { Cut Off } \\ (r>0.30)\end{array} & \text { Intepretasi } \\ & \text { Correlation } & & \end{array}$

\begin{tabular}{|c|c|c|c|}
\hline UIQI & 0.484 & 0.30 & Valid \\
\hline$U I Q 2$ & 0.591 & 0.30 & Valid \\
\hline$U I Q 3$ & 0.451 & 0.30 & Valid \\
\hline UIQ4 & 0.509 & 0.30 & Valid \\
\hline$I Q 1$ & 0.526 & 0.30 & Valid \\
\hline$I Q 2$ & 0.541 & 0.30 & Valid \\
\hline$I Q 3$ & 0.457 & 0.30 & Valid \\
\hline$I Q 4$ & 0.443 & 0.30 & Valid \\
\hline IQ5 & 0.449 & 0.30 & Valid \\
\hline PS1 & 0.609 & 0.30 & Valid \\
\hline PS2 & 0.649 & 0.30 & Valid \\
\hline PS3 & 0.625 & 0.30 & Valid \\
\hline PS4 & 0.575 & 0.30 & Valid \\
\hline$P P 1$ & 0.534 & 0.30 & Valid \\
\hline$P P 2$ & 0.569 & 0.30 & Valid \\
\hline PP3 & 0.658 & 0.30 & Valid \\
\hline PP4 & 0.674 & 0.30 & Valid \\
\hline PP5 & 0.627 & 0.30 & Valid \\
\hline$B 1$ & 0.540 & 0.30 & Valid \\
\hline$B 2$ & 0.603 & 0.30 & Valid \\
\hline B3 & 0.434 & 0.30 & Valid \\
\hline$K 1$ & 0.698 & 0.30 & Valid \\
\hline$K 2$ & 0.698 & 0.30 & Valid \\
\hline$T 1$ & 0.690 & 0.30 & Valid \\
\hline$T 2$ & 0.669 & 0.30 & Valid \\
\hline$T 3$ & 0.602 & 0.30 & Valid \\
\hline$A 1$ & 0.658 & 0.30 & Valid \\
\hline$A 2$ & 0.658 & 0.30 & Valid \\
\hline$P I 1$ & 0.655 & 0.30 & Valid \\
\hline$P I 2$ & 0.573 & 0.30 & Valid \\
\hline$P I 3$ & 0.711 & 0.30 & Valid \\
\hline PI4 & 0.602 & 0.30 & Valid \\
\hline
\end{tabular}

\section{Uji Reliabilitas}

Berikut ini merupakan hasil uji reliabilitas dari keseluruhan responden. Uji reliabilitas menggunakan cronbach's alpha sebagai acuan untuk melihat reliabel atau tidak. Tolak ukur nilai cronbach's alpha yang digunakan adalah lebih dari 0.7 maka dapat disimpulkan bahwa instrumen tersebut sudah reliabel (Mahlhotra, 2012, P.317).

\section{Tabel 1.2}

Hasil Uji Reliabilitas

\begin{tabular}{|l|l|l|}
\hline Variabel & Cronbach's Alpha & Reliabel / NonReliabel \\
\hline User Interface Quality & 0.719 & Reliabel \\
\hline Information Quality & 0.719 & Reliabel \\
\hline Perceived Security & 0.798 & Reliabel \\
\hline Perceived Privacy & 0.818 & Reliabel \\
\hline Belief & 0.705 & Reliabel \\
\hline
\end{tabular}




\section{Persmaan Regresi}

\begin{tabular}{|l|l|l|}
\hline Knowledge & 0.817 & Reliabel \\
\hline Trust & 0.802 & Reliabel \\
\hline Attitude & 0.787 & Reliabel \\
\hline Purchase Intention & 0.811 & Reliabel \\
\hline
\end{tabular}
berikut:

Berdasarkan Model Penelitian, dapat dihasilkan persamaan regresi sebagai

\section{Tabel 1.3}

Persamaan Regresi Variabel User Interface Quality (X1), Information Quality (X2), Perceived Security (X3), Perceived Privacy (X4) terhadap

Trust

Coefficients $^{\mathrm{a}}$

\begin{tabular}{|c|c|c|c|c|c|c|}
\hline \multirow[b]{3}{*}{ Model } & \multicolumn{6}{|c|}{ Coefficients $^{\mathrm{a}}$} \\
\hline & & \multicolumn{2}{|c|}{ Unstandardized Coefficients } & $\begin{array}{l}\text { Standardized } \\
\text { Coefficients }\end{array}$ & & \\
\hline & & B & Std. Error & Beta & $\mathrm{t}$ & Sig. \\
\hline 1 & (Constant) & 2,032 & ,757 & & 2,686 & ,008 \\
\hline & User Interface Quality (X1) & 127 & ,046 & ,139 & 2,749 & ,006 \\
\hline & Information Quality (X2) & ,159 & 054 & 235 & 2,962 & ,003 \\
\hline & Perceived Security (X3) & ,037 & 051 & ,058 & ,732 & ,465 \\
\hline & Perceived Privacy (X4) & 223 & .035 & 361 & 6,437 & 000 \\
\hline
\end{tabular}

a. Dependent Variable: Trust

Berdasarkan tabel diatas maka persamaan regresinya adalah :

Trust $=2.032+0.127$ User Interface Quality +0.159 Information Quality $+\mathbf{0 . 0 3 7}$ Perceived Security +0.223 Perceived Privacy $+e$

Tabel 1.4

Persamaan Regresi Variabel Belief (X5), Knowledge (X6) terhadap Attitude

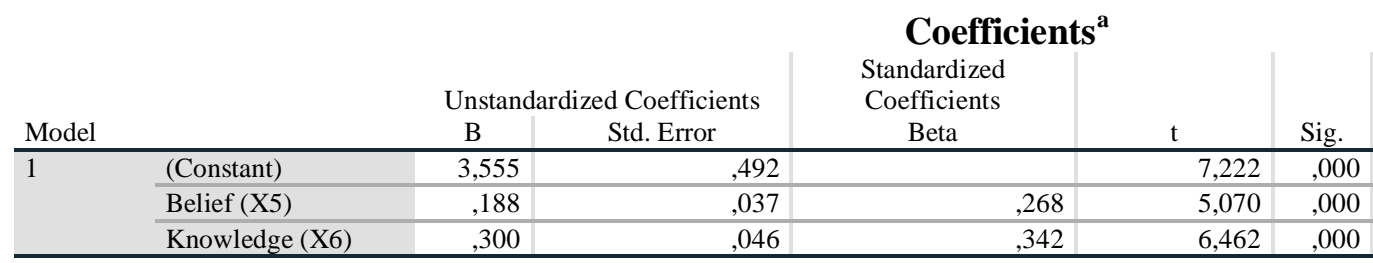

a. Dependent Variable: Attitude

Berdasarkan tabel diatas maka persamaan regresinya adalah: Attitude $=3.555+0.188$ Belief $(X 5)+0.300$ Knowledge $(X 6)+e$

Tabel 1.5

Persamaan Regresi Variabel Trust, Attitude terhadap Niat Beli Coefficients $^{\mathrm{a}}$

\begin{tabular}{|c|c|c|c|c|c|c|}
\hline \multirow[b]{3}{*}{ Model } & \multicolumn{6}{|c|}{ Coefficients $^{\mathrm{a}}$} \\
\hline & & \multicolumn{2}{|c|}{ Unstandardized Coefficients } & \multirow{2}{*}{$\begin{array}{c}\text { Standardized } \\
\text { Coefficients } \\
\text { Beta }\end{array}$} & \multirow[b]{2}{*}{$\mathrm{t}$} & \multirow[b]{2}{*}{ Sig. } \\
\hline & & $\mathrm{B}$ & Std. Error & & & \\
\hline \multirow[t]{3}{*}{1} & (Constant) & ,369 & 1,019 & & ,363 & ,717 \\
\hline & Trust & ,295 & ,077 & , 186 & 3,855 &, 000 \\
\hline & Attitude & 1,305 & ,114 & ,551 & 11,414 & 000 \\
\hline
\end{tabular}

Berdasarkan tabel diatas maka persamaan regresinya adalah:

Niat Beli $=0.369+0.295$ Trust +1.305 Attitude $+e$

Uji Hipotesis

Berikut ini ringkasan hasil uji hipotesis pada penelitian ini:

Hipotesis 1 User Interface Quality berpengaruh signifikan terhadap Trust

Hipotesis 2 Information Quality berpengaruh signifikan terhadap Trust 
Hipotesis 3 Perceived Security tidak berpengaruh signifikan terhadap Trust

Hipotesis 4 Perceived Privacy berpengaruh signifikan terhadap Trust

Hipotesis 5 Belief berpengaruh signifikan terhadap Attitude

Hipotesis 6 Knowledge berpengaruh signifikan terhadap Attitude

Hipotesis 7 Trust berpengaruh signifikan terhadap Niat Beli Barang.

Hipotesis 8 Attitude berpengaruh signifikan terhadap Niat Beli Barang.

3. Hasil Analisis Jalur

\subsection{Pengaruh Langsung}

Berikut adalah hasil ringkasan analisis jalur pada penelitian ini digambarkan pada gambar dibawah ini

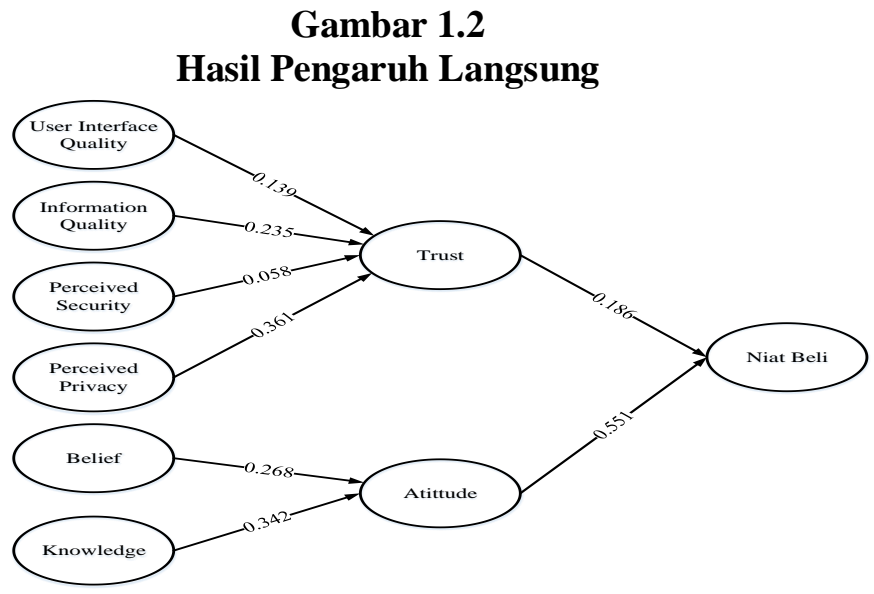

Kesimpulannya adalah Pengaruh User Interface Quality (X1) adalah sebesar 0.139, Pengaruh Information Quality (X2) adalah sebesar 0.235, Pengaruh Perceived Security (X3) adalah sebesar 0.058, dan Pengaruh Perceived Privacy (X4) adalah sebesar 0.361, Pengaruh Beleif (X5) adalah sebesar 0.268, Pengaruh Knowledge (X6) adalah sebesar 0.342, Pengaruh Trust adalah sebesar 0.186, Pengaruh Attitude adalah sebesar 0.551.

\subsection{Pengaruh tidak langsung}

Berikut adalah hasil ringkasan analisis jalur (pengaruh tidak langsung) pada penelitian ini: Hubungan User Interface Quality terhadap Niat Beli $=\mathrm{P}_{\mathrm{x} 1} \mathrm{X}_{\mathrm{y} 1}=$ $(0.139)(0.186)=0.025854$, Hubungan Information Quality terhadap Niat Beli $=\mathrm{P}_{\mathrm{x} 2}$ $\mathrm{X} \mathrm{P}_{\mathrm{y} 1}=(0.235)(0.186)=0.04371$, Hubungan Perceived Security Terhadap Niat Beli $=\mathrm{P}_{\mathrm{x} 3} \mathrm{X} \mathrm{P}_{\mathrm{y} 1}=(0.058)(0.186)=0.010788$, Hubungan Perceived Privacy Terhadap Niat Beli $=\mathrm{P}_{\mathrm{x} 4} \mathrm{X} \mathrm{P}_{\mathrm{y} 1}=(0.361)(0.186)=0.067146$, Hubungan Belief Terhadap Niat Beli $=\mathrm{P}_{\mathrm{x} 5} \mathrm{X} \mathrm{P}_{\mathrm{y} 2}=(0.268)(0.551)=0.147668$, Hubungan Knowledge Terhadap Niat Beli $=\mathrm{P}_{\mathrm{x} 6} \mathrm{X} \mathrm{P}_{\mathrm{y} 2}=(0.342)(0.551)=0.188442$. Kesimpulannya adalah pengaruh tidak langsung antara hubungan User Interface Quality terhadap Niat Beli adalah sebesar 0.025854, pengaruh tidak langsung antara hubungan Information Quality terhadap Niat Beli adalah sebesar 0.04371, pengaruh tidak langsung antara hubungan Perceived Security Terhadap Niat Beli adalah sebesar 0.010788, pengaruh tidak langsung antara hubungan Perceived Privacy Terhadap Niat Beli adalah sebesar 0.067146, pengaruh tidak langsung antara hubungan Belief Terhadap Niat Beli adalah sebesar 0.147668, dan pengaruh tidak langsung antara hubungan Knowledge Terhadap Niat Beli adalah sebesar 0.188442.

\section{KESIMPULAN DAN SARAN}

Terdapat variabel yang mempengaruhi Trust yaitu User Interface Quality, Information Quality, Perceived Privacy. Menurut pengguna, variabel User Interface Quality, Infomation Quality, Perceived Privacy dianggap penting untuk mendapatkan kepercayaan pengguna website E-Commerce di Indonesia. Sedangkan variabel 
Perceived Security tidak mempengaruhi variabel Trust secara signifikan. Variabel lain seperti tingkat keyakinan (Belief), dan ilmu pengetahuan (Knowledge), berpengaruh signifikan terhadap sikap (Attitude) seseorang untuk bertindak atau melakukan transaksi di website E-Commerce di Indonesia.

Penelitian selanjutnya diharapkan dapat menggunakan metode yang sama dengan penelitian ini. Tujuannya adalah sebagai bahan evaluasi dan pengembangan yang lebih optimal tentang pengaruh niat beli di website E-Commerce di Indonesia.

\section{DAFTAR PUSTAKA}

Coulter, K. Determinants of Trust in a services provider: the moderating role of length of relationship. Journal of services marketing, Vol. 24, 4:47-72, 2008.

Efraim Turban, David King, Dennis Vichland, Jae Lee. 2006. Electronic Commerce a Managerial Perspective 2006 New Jersey. Pearson Prentice Hall. P.3.

Eid, M. \& F. Al-Anazi. Factors Influencing Saudi Consumers Loyalty toward B2C ECommerce. 14th Americas Conference on Information System. Toronto, Ontario, Canada.

Ghozali, Imam. 2013. Aplikasi Analisis Multivariate dengan Program SPSS.

Hawkins. D.I. and Mothersbaugh, D.L. 2010. Consumer Behavior: Building Marketing Strategy. 11th Edition. McGraw-Hill, Irwin.

J, Supranto. 2012. Metode Riset. Jakarta: Rineka Cipta.

Kolsaker, A. \& Payne, C. 2002. Engendering Trust in E-Commerce: a Study of Gender-based Concerns, Marketing Intelligence \& Planning, 20 (4): 206-214.

Kotler, Philip. (2012). Marketing Management. 14th Edition. New Jersey: Pearson Education, Inc., Prentice Hall

Laudon. Kenneth C. \& Jane P. Laudon. 2010. Manajemen Information System: Managing the digital firm. New jersey. Prentice-Hall.

Park, C.H., \& Kim, Y. G. (2003). Identifying Key Factors Affecting Consumer Purchase Behavior In An Online Shopping Context. International Journal of Retail \& Distribution Management, Vol.31, No.1, pp.16-29.

Shneiderman, Ben \& Plaisant, Catherine. (2010). Designing The User Interface: Strategies For Effective Human-Computer Interaction (5th ed). United States of America: Pearson Education, Inc

Uma Sekaran. 2006. Metodologi Penelitian Untuk Bisnis. Jakarta: Salemba Empat

Yousafzai, S. Y., Palister, J. G., dan Foxall, G. R. 2003. A proposed model of ETrust for Electronic Banking, Technovation, 23: 847-860. 
